\title{
Production dynamics of extracellular proteases accompanying morphological differentiation of Streptomyces albidoflavus SMF301
}

\author{
Sung Gyun Kang, In Seop Kim, Yong Taik Rho and Kye Joon Lee
}

Department of

Microbiology, College of

Natural Sciences, and

Research Centre for

Molecular Microbiology,

Seoul National University,

Seoul 151-742, Korea

\author{
Author for correspondence: Kye Joon Lee. Tel: +82 2880 6705. Fax: +82 2882 9285/888 4911. \\ e-mail: LKJ12345@alliant.snu.ac.kr
}

Keywords: Streptomyces albidoflavus, trypsin-like protease, metalloprotease, submerged spore, morphological differentiation

\section{INTRODUCTION}

Aerial spore formation by streptomycetes on solid culture follows aerial mycelium formation, which is stimulated by limiting essential nutrients (Chater, 1984; Hopw̌ood et al., 1970). The growth of aerial mycelium and formation of spores is supported by the utilization of degraded substrate mycelium (Chater, 1989, 1993; Granozzi et al., 1990) because the aerial mycelium has limited access to nutrients (Mendez et al., 1985). Physiological and morphological differentiation in streptomycetes are closely regulated by nitrogen nutrition; extracellular proteases participate in the assimilation of external proteinaceous nitrogen sources (Shapiro, 1989). Although the precise mechanism and role of proteases in growth and differentiation are not well understood, serine protease expressed in stationary-phase cultures of Streptomyces peucetius and Streptomyces lactamdurans is reported to regulate the turnover metabolism associated with formation of secondary metabolites and morphogenesis (Gibb \& Strohl, 1988; Ginther, 1978).
A recent study of the regulation of protease activities during growth and mycelium development concluded that a trypsin-like protease (TLP) was essential for the degradation of mycelial protein in Streptomyces exfoliatus SMF13, and that protease production was regulated by an endogenous inhibitor (Kim \& Lee, 1995).

Sporulation can take place in submerged cultures of some Streptomyces spp. (Kendrick \& Ensign, 1983; Daza et al., 1989; Koepsel \& Ensign, 1984; Glazebrook et al., 1990), providing greater possibilities for physiological analysis. Streptomyces albidoflavus SMF301 produces abundant spores in submerged and solid cultures (Rho et al., 1992). The physical and chemical properties of submerged spores and aerial spores have been compared (Lee \& Rho, 1993), and the kinetics of spore formation reported (Rho \& Lee, 1994). To study the possible role of proteases in differentiation, the activities of extracellular proteases in relation to morphological differentiation in submerged and solid cultures were characterized and extracellular proteases in the culture broth of $S$. albidoflavus were purified.

\section{METHODS}

Micro-organism and media. Streptomyces albidoflavus SMF301 (Rho et al., 1992) and bald mutants were used. Bald mutants were derived by UV irradiation and cultivation at high 
temperature (Hara \& Beppu, 1982; Hopwood et al., 1985). Stock culture medium consisted of $(\mathrm{w} / \mathrm{v}): 1 \%$ glucose, $0.2 \%$ peptone, $0.3 \%$ yeast extract, $0.1 \%$ beef extract and $1.8 \%$ agar for solid culture. The seed medium and the main culture medium consisted of (w/v): $0.5 \%$ glucose, $0.5 \%$ sodium caseinate, $0.01 \% \mathrm{KH}_{2} \mathrm{PO}_{4}, 0.03 \% \quad \mathrm{MgSO}_{4} .7 \mathrm{H}_{2} \mathrm{O}, 0.001 \%$ $\mathrm{FeSO}_{4} .7 \mathrm{H}_{2} \mathrm{O}, 0.001 \% \mathrm{CuSO}_{4} .5 \mathrm{H}_{2} \mathrm{O}, 0.001 \% \mathrm{CaCl}_{2} .2 \mathrm{H}_{2} \mathrm{O}$ and $0.0003 \% \mathrm{MnCl}_{2} \cdot 4 \mathrm{H}_{2} \mathrm{O}$. The initial $\mathrm{pH}$ of the media was adjusted to 7.0 before steam sterilization. Phosphate and other salts were separately sterilized by membrane filtration $(0 \cdot 2 \mu \mathrm{m}$, Millipore).

Strain maintenance and culture conditions. Strains were maintained by transfer to slopes of stock culture medium each month, and were stored at $4{ }^{\circ} \mathrm{C}$. For solid cultures, about $10^{3}$ spores harvested from the stock culture agar medium were inoculated evenly on the main agar culture medium and incubated at $28^{\circ} \mathrm{C}$. For submerged batch culture, one loopful of mycelium and spores was used to inoculate $30 \mathrm{ml}$ seed culture medium and incubated at $28^{\circ} \mathrm{C}$ for $2 \mathrm{~d}$. The seed culture was used to inoculate $3 \mathrm{l}$ of the main culture medium contained in a jar fermenter (model KF-5L, Korea Fermentor). The culture temperature was maintained at $28^{\circ} \mathrm{C}$ and the initial $\mathrm{pH}$ was controlled at $7 \cdot 0$. Agitation and aeration were 200 r.p.m. and $1 \mathrm{v}$ $\mathrm{v}^{-1} \min ^{-1}$, respectively.

Observation of mycelium morphology and growth. Morphological characteristics were observed with a phase-contrast microscope (Nikon Laphot) and a scanning electron microscope (Stereoscan $260 \mathrm{SEM}$ ). Colonies developed on agar medium were fixed using the following procedures. Phosphate-buffered glutaraldehyde solution $(8 \%, \mathrm{v} / \mathrm{v}$; $\mathrm{pH} 7.4$ ) was poured into holes punched around colonies. Plates were left for $24 \mathrm{~h}$ at $4{ }^{\circ} \mathrm{C}$; colonies were cut out to the minimal size from the agar medium and then dried in a sealed Revco box under $\mathrm{P}_{2} \mathrm{O}_{5}$ at $4{ }^{\circ} \mathrm{C}$. Dried colonies were gold-coated with a Polaron SC502 sputter coater (Fisons) at $15 \mathrm{~mA}$ for $1 \mathrm{~min}$ under vacuum conditions. The morphology of colonies was observed with a Stereoscan 260 scanning electron microscope (Cambridge).

To measure mycelium growth, mycelium was harvested by centrifugation $(10000 \mathrm{~g}, 10 \mathrm{~min})$ and washed twice with physiological saline solution and once with distilled water. The washed mycelium was collected by vacuum filtration (Whatman GF/C paper), dried at $80^{\circ} \mathrm{C}$ for $24 \mathrm{~h}$, and weighed.

Measurement of submerged spore formation. The culture broth $(5 \mathrm{ml})$ was sonicated for $5 \mathrm{~min}$ at $100 \mathrm{~W}$ using a sonic dismembrator (model 300, Fisher). The sonicated suspension $(0.5 \mathrm{ml})$ was mixed gently with $0.1 \mathrm{M} \mathrm{HCl}(4.5 \mathrm{ml})$ and the mixture was allowed to stand for $5 \mathrm{~min}$ before it was diluted in physiological saline and spread on rich agar medium. Colonies were counted after $4 \mathrm{~d}$ incubation to give initial spore numbers (Lee \& Rho, 1993).

Assay of proteases. The culture broth was centrifuged at $10000 \mathrm{~g}$ for $10 \mathrm{~min}$ and the supernatant was used for assay. Total protease activity was estimated by measuring the concentration of tyrosine liberated from Hammarsten casein (Merck) at $37^{\circ} \mathrm{C}$ and $\mathrm{pH} 7.5$ (Tris/ $\mathrm{HCl}$ buffer, $0.1 \mathrm{M}$ ) for $15 \mathrm{~min}$. One unit of casein hydrolytic activity (caseinase) was defined as the amount of enzyme needed to produce $1 \mu \mathrm{g}$ tyrosine equivalent $\mathrm{min}^{-1}$ from the casein (Narahashi, 1970). Hydrolytic activity for synthetic substrates was estimated by measuring the amount of $p$-nitroanilides liberated from various synthetic substrates: $N$-benzoyl-tyrosine $p$-nitroanilide [BTPNA; the specific synthetic substrate of chymotrypsin-like protease (CTP)], $N$-benzoyl-arginine $p$-nitroanilide (BAPNA; the specific synthetic substrate of TLP) and leucyl $p$-nitroanilide [LPNA; the specific synthetic substrate of metalloprotease (MTP)]. Enzyme reactions were carried out with $200 \mu \mathrm{M}$ aminoacyl $p$-nitroanilides at $35^{\circ} \mathrm{C}$ and $\mathrm{pH} 7.5$ (Tris/ $\mathrm{HCl}$ buffer, $0 \cdot 1 \mathrm{M})$. The activity was calculated from the linear part of the curve, using $\varepsilon_{405}=9620 \mathrm{~mol}^{-1} \mathrm{~cm}^{-1}$. One unit of hydrolytic activity was defined as the amount of enzyme needed to produce $1 \mu \mathrm{mol} p$-nitroanilide $\mathrm{min}^{-1}$ (Sarath et al., 1989).

Purification of proteases. The culture broth was harvested by centrifugation $(10000 \mathrm{~g}, 15 \mathrm{~min})$ and fractionated as follows.

(1) Ammonium sulfate precipitation. The culture broth was brought to $45 \%$ saturation with ammonium sulfate followed by centrifugation $(20000 \mathrm{~g}, 30 \mathrm{~min})$. The supernatant was brought to $90 \%$ saturation with ammonium sulfate and then centrifuged at $20000 \mathrm{~g}$ for $30 \mathrm{~min}$. The fraction precipitated between 45-90\% ammonium sulfate saturation was dissolved in distilled water and desalted by ultrafiltration.

(2) Gel-permeation chromatography. The active fraction obtained from the ammonium sulfate fractionation was applied to a column of Sephadex G-75 equilibrated with $0 \cdot 1 \mathrm{M}$ Tris $/ \mathrm{HCl}$ $(\mathrm{pH} 7 \cdot 5)$ and then eluted with the same buffer.

(3) Chromatography on DEAE-Sephadex. The active fraction from the gel-permeation chromatography was applied to a column of DEAE-Sephadex A-50 equilibrated with $0.1 \mathrm{M}$ Tris $/ \mathrm{HCl}$ $(\mathrm{pH} \mathrm{7.5)}$ and $0.2 \mathrm{M} \mathrm{NaCl}$, and then eluted with the same buffer and a linear gradient of $\mathrm{NaCl}(0.2 \mathrm{M}-0.7 \mathrm{M})$. The active fraction was concentrated by ultrafiltration in $0.01 \mathrm{M}$ Tris $/ \mathrm{HCl}$ buffer (pH 7.5).

(4) Chromatography on QAE-Sephadex. The active fraction from the DEAE-Sephadex was applied to a column of QAESephadex A-50 equilibrated with $0.01 \mathrm{M}$ Tris/ $\mathrm{HCl}(\mathrm{pH} 7.5$ ), and then eluted with the same buffer and a linear gradient of $\mathrm{NaCl}(0 \mathrm{M}-0.7 \mathrm{M})$. The active fraction was concentrated by ultrafiltration in $0.01 \mathrm{M}$ Tris/ $\mathrm{HCl}(\mathrm{pH} \mathrm{7.5)}$.

Effect of $\mathrm{pH}$ and temperature. Optimum $\mathrm{pH}$ for the hydrolysis of specific synthetic substrates was measured over a range of $\mathrm{pH} 3 \cdot 0-11 \cdot 0$. The effect of $\mathrm{pH}$ on enzyme stability was determined by preincubation for $90 \mathrm{~min}$ at $30^{\circ} \mathrm{C}$ in the same range of $\mathrm{pH}$ and the remaining activity was measured at the optimum $\mathrm{pH}$. Optimum temperature was determined within a range of $20-60^{\circ} \mathrm{C}$ at the optimum $\mathrm{pH}$. For evaluation of thermal stability, the enzyme solution was held at various temperatures and the remaining activity was measured as a function of reaction time at the optimum temperature.

Substrate specificity and effect of inhibitors. The kinetic parameters for synthetic substrates were measured by the procedures described above. For the determination of kinetic parameters, the concentrations of synthetic substrates were from $2.5 \mu \mathrm{M}$ to $1000 \mu \mathrm{M}$. Protease inhibitors, including leupeptin, antipain, $N \alpha$-p-tosyl-L-lysine chloromethyl ketone (TLCK), $N$-tosyl-L-phenylalanine chloromethyl ketone (TPCK), EDTA, amastatin, EGTA, penanthroline and E-64 were preincubated with the protease solution for $5 \mathrm{~min}$. The protease activity remaining was measured. The percentage inhibition was calculated from the following relationship: percentage inhibition $=100\{(A-B) / A\}$, where $A$ is protease activity without the inhibitor and $B$ is protease activity with the inhibitor (Aoyagi et al., 1969).

Chemicals, reagents and reproducibility. All synthetic substrates and enzyme inhibitors were purchased from Sigma. Experiments were carried out in triplicate, and mean values are given. 


\section{RESULTS}

Mycelium growth, submerged spore formation, and
production of extracellular proteases in batch culture

The substrate specificity and inhibition profile of extracellular proteases in S. albidoflavus SMF301 cultures were evaluated (Table 1). Specific synthetic substrates such as BTPNA (for CTP), BAPNA (for TLP), and LPNA (for MTP) were hydrolysed effectively. The inhibition specificity was also evaluated for each protease: BTPNAhydrolysing activity was inhibited by chymostatin and TPCK; BAPNA-hydrolysing activity was inhibited by leupeptin, TLCK, and antipain; LPNA-hydrolysing activity was inhibited by EDTA, EGTA and amastatin. It was concluded that $S$. albidoflavus SMF301 produces at least three types of protease: the activity on BTPNA is due to a CTP, that on BAPNA is due to a TLP and that on LPNA is due to an MTP (Table 1).

Changes in mycelium growth, submerged spore formation and the activities of CTP, TLP and MTP during batch culture are shown in Fig. 1. Biomass increased as the spores germinated, but new spores were formed from the middle of the exponential growth phase and the biomass declined without an extended stationary phase (Fig. 1a). CTP was the major extracellular protease when sodium caseinate was used as a sole nitrogen source, and mycelium growth was associated with the activity of CTP (Fig. 1b). TLP and MTP started to be produced just before the onset of submerged spore formation. The activity of MTP was high in the decline phase, but that of TLP decreased earlier than MTP (Fig. 1b). Submerged spore formation correlated with the increased activities of TLP and MTP (Fig. 1c).

\section{Effects of external addition of specific protease inhibitors on mycelium growth and submerged spore} formation

To assess whether proteases have a role in growth and differentiation, individual protease activities were eliminated from the culture by adding specific inhibitors
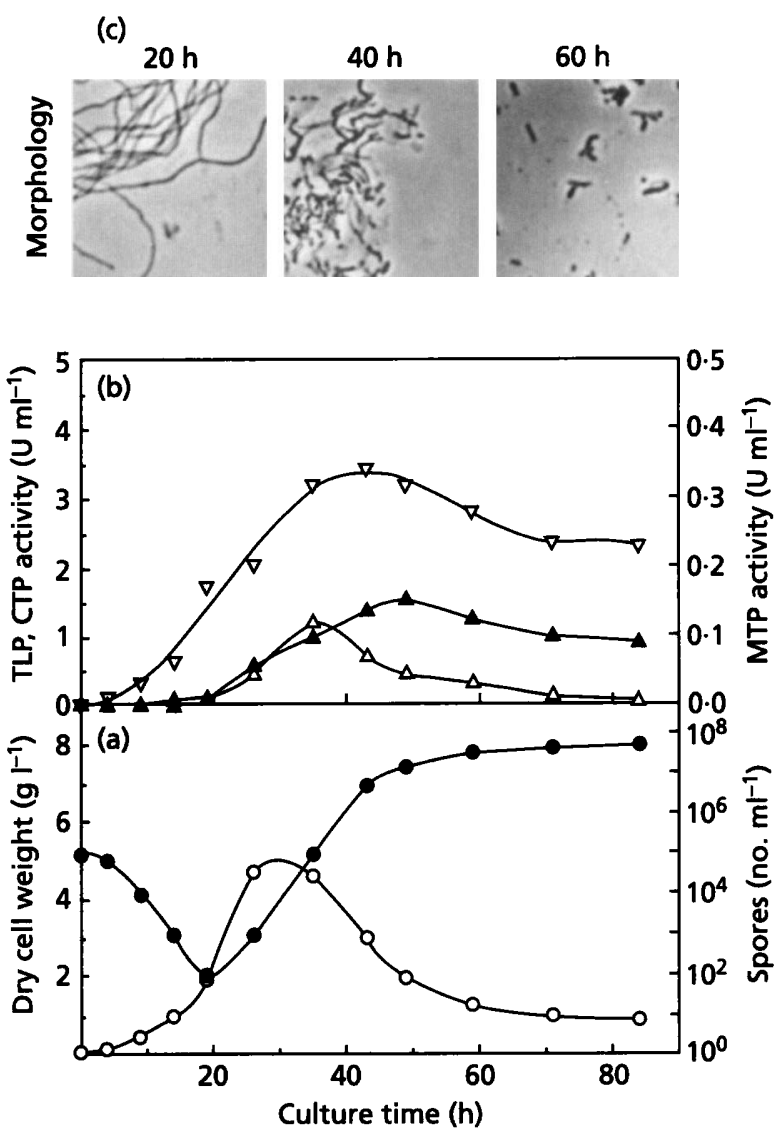

Fig. 1. Changes in growth, concentration of submerged spores, CTP, TLP and MTP, and morphology during submerged culture of $S$. albidoflavus SMF301. (a) Growth (O) and submerged spores (O); (b) CTP $(\nabla)$, TLP $(\triangle)$ and MTP $(\Delta)$; (c) morphology.

(TPCK, TLCK, amastatin and EDTA). Spore germination and further mycelium growth were completely inhibited by adding the CTP inhibitor TPCK $(0 \cdot 1 \mathrm{mM})$ at the beginning of the culture (data not shown). When TPCK was added at $24 \mathrm{~h}$, CTP activity was inhibited

Table 1. Effect of protease inhibitors on hydrolysis of synthetic substrates by broth of S. albidoflavus SMF301

The protease activity was mixed with $100 \mu \mathrm{l}$ cell-free broth from $36 \mathrm{~h}$ and $48 \mathrm{~h}$ cultures. After preincubation for $5 \mathrm{~min}$, the rate of BAPNA, BTPNA and LPNA hydrolysis was measured. Hydrolytic activity is given as $\mathrm{Uml}^{-1}$ with the degree of inhibition (\%) in parentheses.

\begin{tabular}{|c|c|c|c|c|c|c|c|c|c|c|}
\hline \multirow[t]{2}{*}{ Substrate } & \multicolumn{10}{|c|}{ Inhibitor (final concentration) } \\
\hline & Control & $\begin{array}{c}\text { Leupeptin } \\
(50 \mu \mathrm{M})\end{array}$ & $\begin{array}{c}\text { Antipain } \\
(50 \mu M)\end{array}$ & $\begin{array}{c}\text { Chymostatin } \\
(50 \mu \mathrm{M})\end{array}$ & $\begin{array}{c}\text { TLCK } \\
(50 \mu M)\end{array}$ & $\begin{array}{c}\text { TPCK } \\
(50 \mu M)\end{array}$ & $\begin{array}{c}E-64 \\
(50 \mu M)\end{array}$ & $\begin{array}{r}\text { EDTA } \\
(1 \mathrm{mM})\end{array}$ & $\begin{array}{c}\text { EGTA } \\
(1 \mathrm{mM})\end{array}$ & $\begin{array}{c}\text { Amastatin } \\
(1 \mathrm{mM})\end{array}$ \\
\hline \multirow[t]{2}{*}{ BAPNA } & $1 \cdot 23$ & $0 \cdot 01$ & 0.02 & 0.95 & 0.01 & 0.89 & $1 \cdot 14$ & 0.98 & 0.95 & $1 \cdot 17$ \\
\hline & & $(100)$ & (99) & (23) & $(100)$ & $(28)$ & $(8)$ & $(21)$ & $(23)$ & (5) \\
\hline \multirow[t]{2}{*}{ BTPNA } & $4 \cdot 32$ & $4 \cdot 13$ & $4 \cdot 12$ & $2 \cdot 53$ & $4 \cdot 25$ & 1.62 & $4 \cdot 26$ & $4 \cdot 12$ & $4 \cdot 25$ & $4 \cdot 32$ \\
\hline & & (5) & (5) & $(42)$ & $(2)$ & $(43)$ & $(2)$ & (5) & $(2)$ & $(0)$ \\
\hline \multirow[t]{2}{*}{ LPNA } & $0 \cdot 23$ & $0 \cdot 21$ & $0 \cdot 23$ & $0 \cdot 20$ & $0 \cdot 22$ & $0 \cdot 24$ & $0 \cdot 26$ & $0 \cdot 02$ & 0.01 & 0.02 \\
\hline & & $(8)$ & $(0)$ & (14) & $(5)$ & $(0)$ & $(0)$ & (92) & $(96)$ & (92) \\
\hline
\end{tabular}


(c)
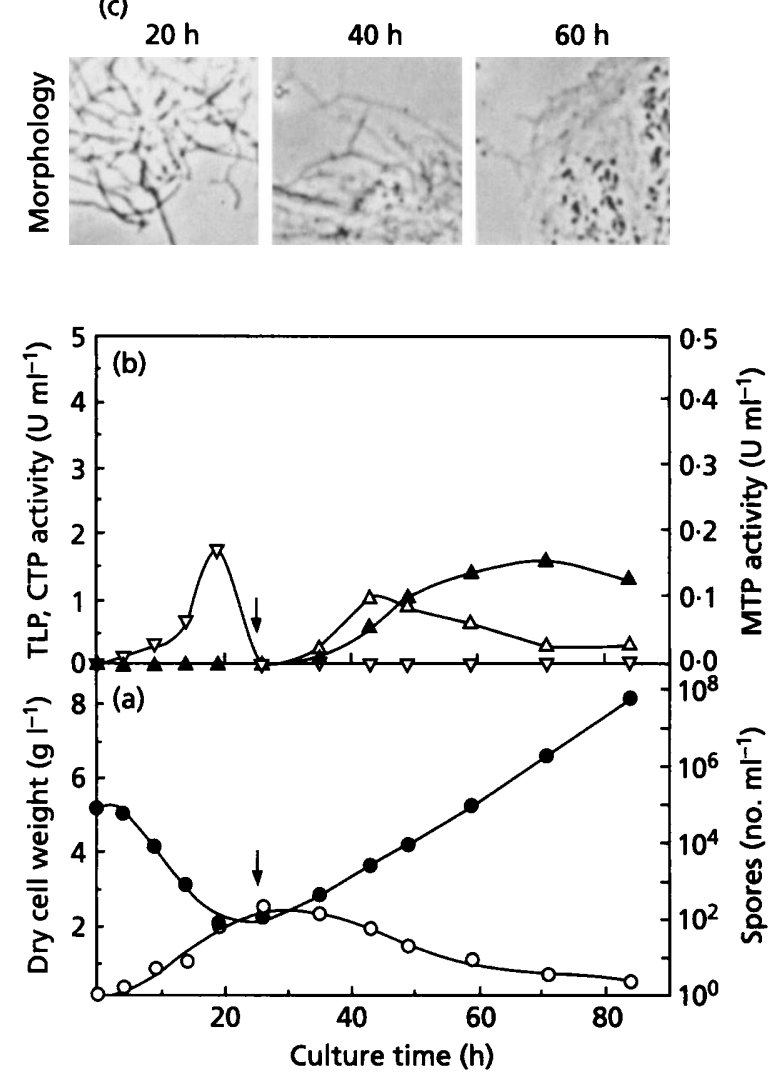

Fig. 2. Effects of TPCK on growth, submerged spore formation, CTP, TLP and MTP, and changes in morphology during submerged culture of S. albidoflavus SMF301. TPCK was added to the culture at the time indicated ( $\downarrow$ ). (a) Growth $(O)$ and submerged spores (O); (b) CTP $(\nabla)$, TLP $(\triangle)$ and MTP $(\Delta)$; (c) morphology.

immediately, whereas the activities of TLP and MTP were not greatly changed. Mycelium growth was also inhibited immediately, but the mycelium differentiated slowly and continuously to give submerged spores (Fig. 2a-c).

When the TLP inhibitor TLCK $(0 \cdot 1 \mathrm{mM})$ was added to the culture broth at $24 \mathrm{~h}$, submerged spore formation was suppressed, but mycelium growth was not greatly affected (Fig. 3a). The activity of TLP was completely inhibited but CTP and MTP were not affected (Fig. 3b). Mycelial fragmentation or submerged spore formation was rarely observed in the presence of TLCK (Fig. 3c).

When MTP inhibitor (EDTA, $0.1 \mathrm{mM}$ or amastatin, $0.1 \mathrm{mM}$ ) was added to the culture broth at $24 \mathrm{~h}$, submerged spore formation was completely suppressed, but mycelium growth was not affected (Fig. 4a). No MTP activity was detected during the $80 \mathrm{~h}$ incubation, while the activity of CTP increased late in the culture (Fig. 4b). From microscopic observations, the tips and other parts of the mycelium were thickened, but no submerged spores were detected (Fig. 4c).

Mycelium growth and production of CTP, TLP and MTP (c)
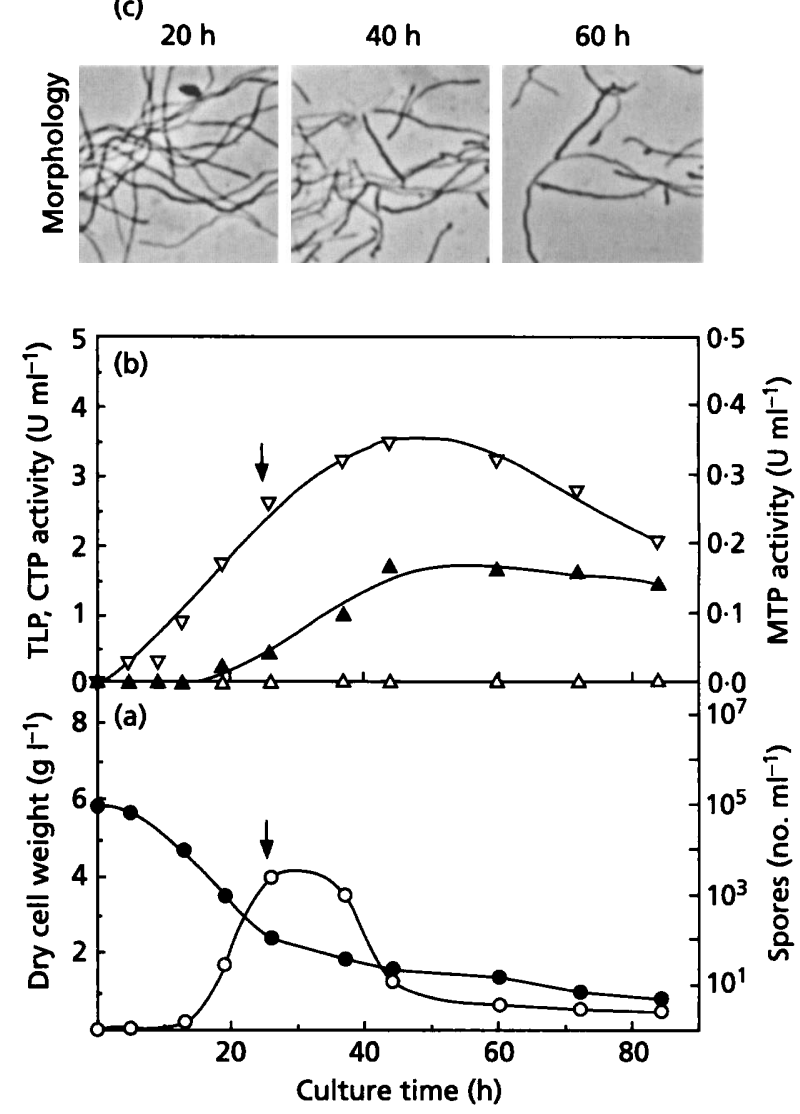

Fig. 3. Effects of TLCK on growth, submerged spore formation, CTP, TLP and MTP, and changes in morphology during submerged culture of S. albidoflavus SMF301. TLCK was added to the culture at the time indicated $(\downarrow)$. (a) Growth $(O)$ and submerged spores (O); (b) CTP $(\nabla)$, TLP $(\triangle)$ and MTP ( $\Delta)$; (c) morphology.

in a submerged culture of a bald mutant are shown in Fig. 5. The mutant grew well but submerged spore formation and mycelium autolysis did not occur (Fig. 5c). The production of CTP was the same as in the parent strain, and was closely related to mycelium growth, but TLP and MTP were not found in the culture supernatant solution (Fig. 5a, b).

\section{Effects of external addition of specific protease inhibitors on substrate mycelium, aerial mycelium and aerial spore formation}

On agar medium and in the absence of protease inhibitors, S. albidoflavus SMF301 grew with the sequential formation of substrate mycelium, aerial mycelium and aerial spores (Fig. 6a). However, substrate mycelium growth was completely inhibited by the CTP inhibitor; addition of TPCK $(0.1 \mathrm{mM})$ to the centre of an agar plate gave a clear zone (data not shown). When TLP inhibitor (TLCK, $0.1 \mathrm{mM}$ ) was added in this way, aerial mycelium growth and further aerial spore formation in the region appeared to be inhibited (Fig. 6b). However, substrate mycelium 
(c)
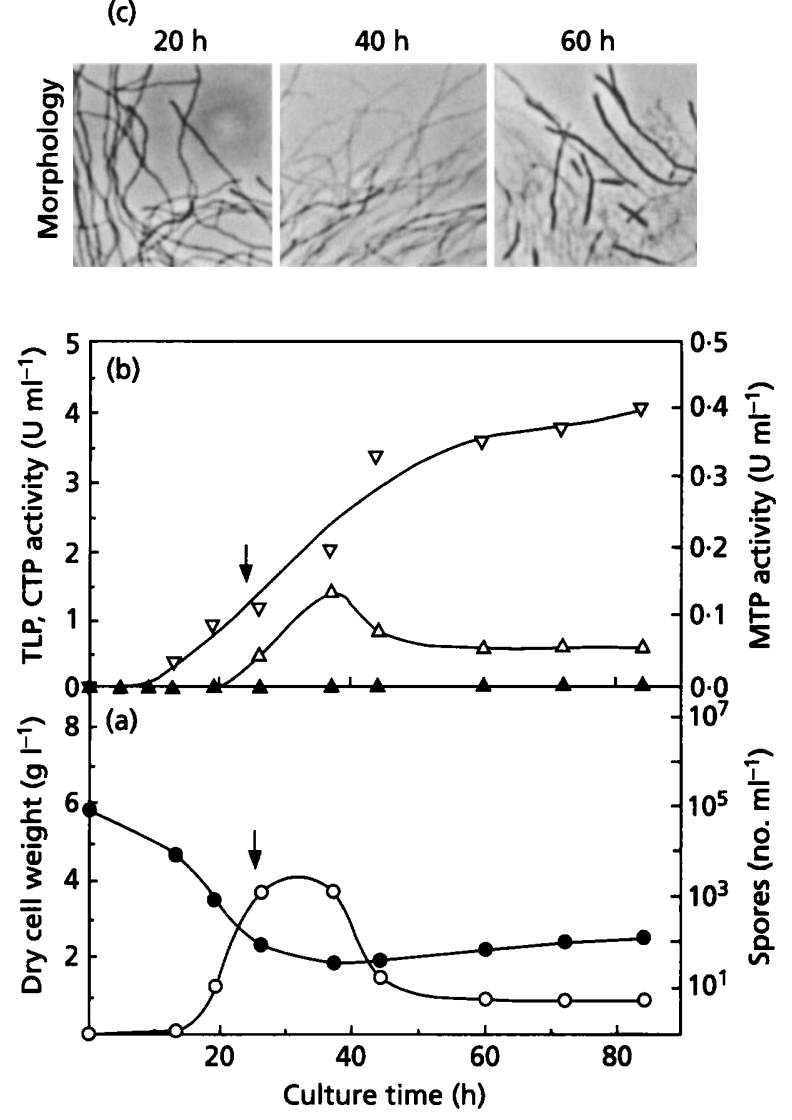

Fig. 4. Effects of EDTA on growth, submerged spore formation, CTP, TLP and MTP, and changes in morphology during submerged culture of $S$. albidoflavus SMF301. EDTA was added to the culture at the time indicated ( $\downarrow)$. (a) Growth (O) and submerged spores (O); (b) CTP $(\nabla), \operatorname{TLP}(\triangle)$ and MTP $(\Delta)$; (c) morphology.

growth was not inhibited, suggesting that TLP played a role in mycelium differentiation but not in the substrate mycelium growth. Substrate mycelium growth as well as aerial mycelium growth were not inhibited at $0.1 \mathrm{mM}$ by the MTP inhibitors EDTA or amastatin, whereas aerial spore formation was completely inhibited (Fig. 6c). The results suggested that MTP might participate in the formation of spores from aerial mycelium.

\section{Purification and characterization of proteases}

Since TLP and MTP might be involved in the morphological differentiation of $S$. albidoflavus SMF301, the proteases were purified from the culture broth (Table 2a, b). Molecular masses of the purified TLP and MTP were estimated by SDS-PAGE to be $32 \mathrm{kDa}$ and $18 \mathrm{kDa}$, respectively (Fig. 7a, b).

The purified TLP was stable from $\mathrm{pH} 6$ to 9 but the optimum $\mathrm{pH}$ for the hydrolysis of a synthetic substrate (BAPNA) was $\mathrm{pH}$ 9. The optimum temperature was $40^{\circ} \mathrm{C}$; TLP was unstable at temperatures above $45^{\circ} \mathrm{C}$
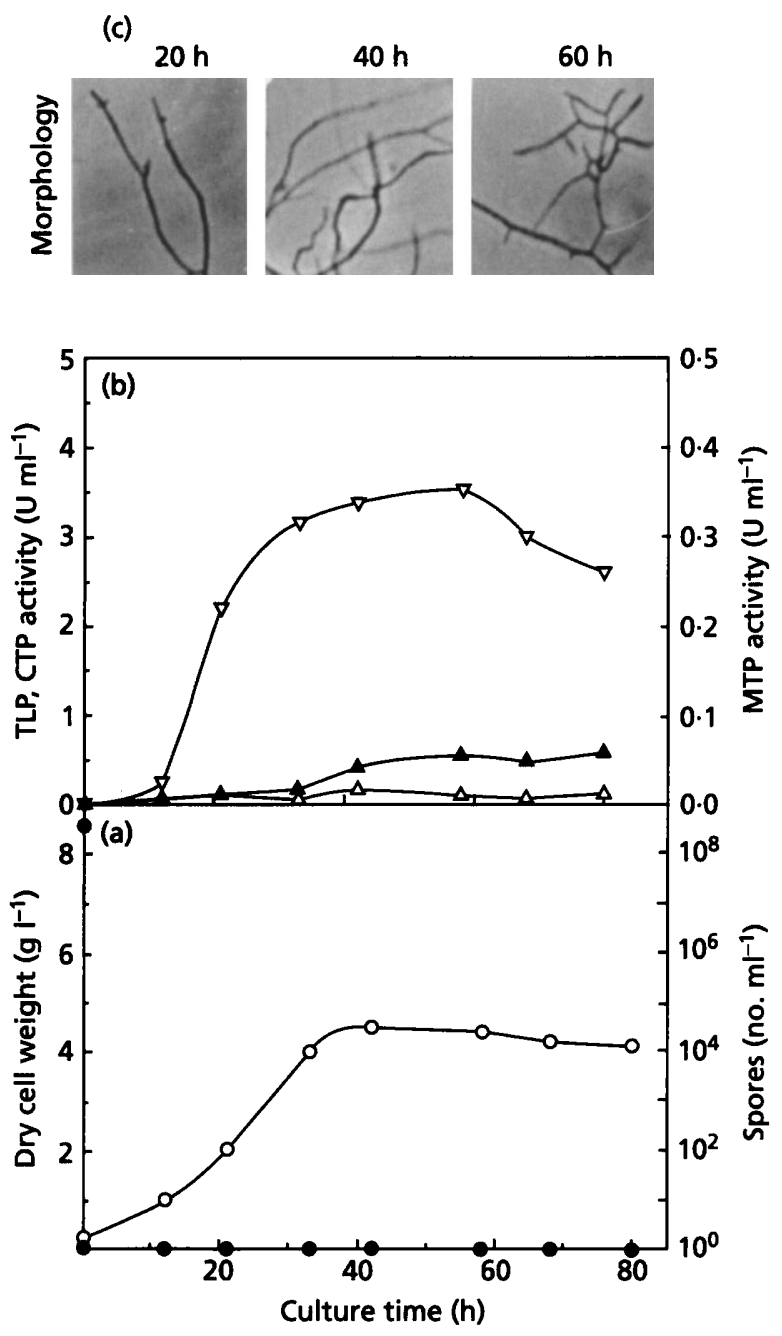

Fig. 5. Changes in growth, concentration of submerged spores, CTP, TLP and MTP, and morphology in submerged culture of a bald mutant of S. albidoflavus SMF301. (a) Growth $(O)$ and submerged spores (O); (b) CTP $(\nabla), \operatorname{TLP}(\triangle)$ and MTP $(\Delta)$; (c) morphology.

(Table 3). The $K_{\mathrm{m}}$ and $V_{\max }$ values for BAPNA under optimum conditions were $139 \mu \mathrm{M}$ and $10 \mathrm{nmol} \mathrm{min}^{-1}$, respectively. TLP was competitively inhibited by leupeptin and the inhibition constant of leupeptin $\left(K_{\mathbf{i}}\right)$ was $0.0031 \mu \mathrm{M}$ ('Table 3 ). The activity of TLP was not affected by $\mathrm{Ca}^{2+}, \mathrm{Mg}^{2+}$ and $\mathrm{Mn}^{2+}$ at a concentration of $5 \mathrm{mM}$, but $\mathrm{Hg}^{2+}$ brought about a decrease in the activity (Table 4).

The optimum $\mathrm{pH}$ for hydrolysis of a synthetic substrate (LPNA) by MTP was $\mathrm{pH} 8$ and the optimum temperature was $55^{\circ} \mathrm{C}$. The enzyme was stable in the range of $\mathrm{pH}$ 6-9, and below $55^{\circ} \mathrm{C}$. The $K_{\mathrm{m}}$ and $V_{\max }$ values for LPNA were $58.9 \mu \mathrm{M}$ and $3.47 \mathrm{nmol} \mathrm{m^{-1 }}$, respectively (Table 3 ). The activity of MTP was stimulated by $\mathrm{Co}^{2+}$ and $\mathrm{Ca}^{2+}$ at a concentration of $5 \mathrm{mM}$, but $\mathrm{Mn}^{2+}, \mathrm{Mg}^{2+}$ and $\mathrm{Zn}^{2+}$ did not affect the activity, and $\mathrm{Hg}^{2+}$ decreased the activity (Table 4). 
1

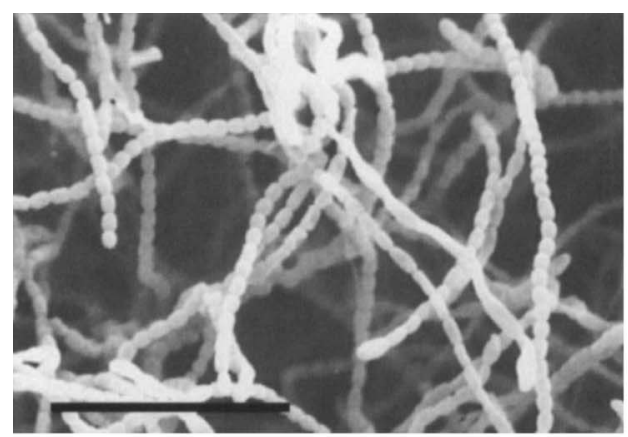

(b)

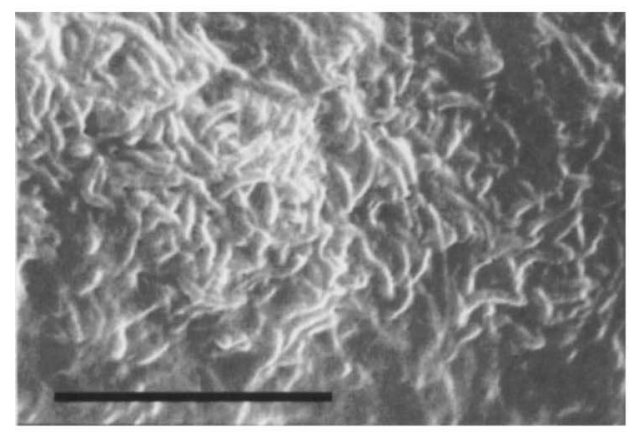

(c)

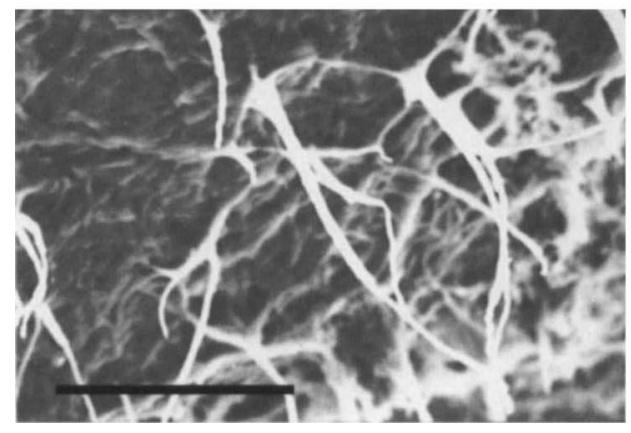

2
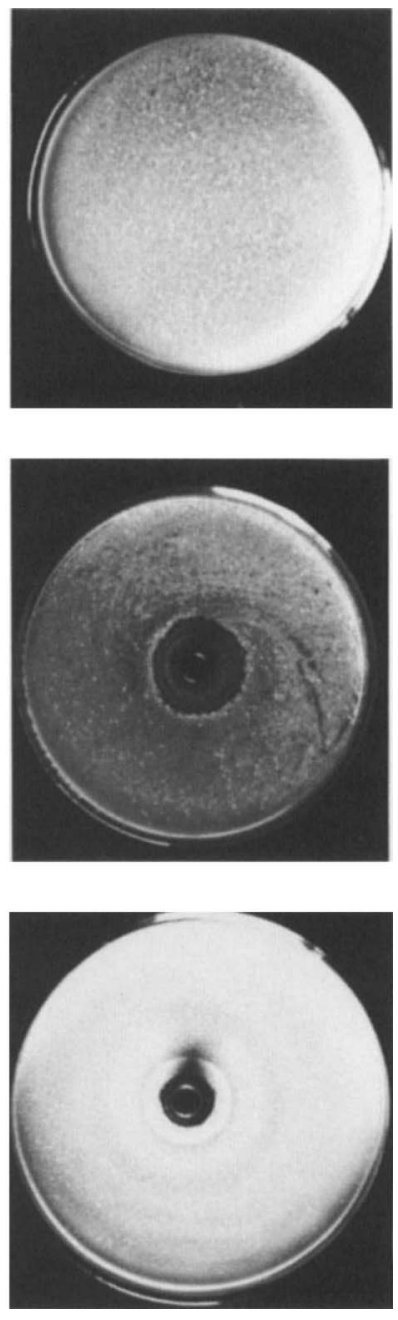

Fig. 6. Morphological characteristics of $S$. albidoflavus SMF301 grown on solid culture with protease inhibitors. (a) No addition of protease inhibitors; (b) addition of TLP inhibitor ( $0.1 \mathrm{mM}$ TLCK); (c) addition of MTP inhibitor ( $0.1 \mathrm{mM}$ EDTA). Lanes: 1, scanning electron micrographs; 2, photographs of solid cultures. Scale-bars indicate $10 \mu \mathrm{m}$, $10 \mu \mathrm{m}$ and $20 \mu \mathrm{m}$ in (a), (b) and (c) (lane 1), respectively.

Table 2. Purification of TLP and MTP from S. albidoflavus SMF301

\begin{tabular}{|c|c|c|c|c|c|}
\hline Purification step & $\begin{array}{l}\text { Protein } \\
\text { (mg) }\end{array}$ & $\begin{array}{l}\text { Activity } \\
\text { (U) }\end{array}$ & $\begin{array}{c}\text { Specific activity } \\
{\left[\mathrm{U}\left(\mathrm{mg} \mathrm{protein}^{-1}\right)\right]}\end{array}$ & $\begin{array}{l}\text { Purification } \\
\text { (-fold) }\end{array}$ & $\begin{array}{l}\text { Yield } \\
(\%)\end{array}$ \\
\hline \multicolumn{6}{|c|}{ (a) Purification of TLP } \\
\hline Culture broth & 720 & 856 & $1 \cdot 2$ & $1 \cdot 0$ & 100 \\
\hline $\begin{array}{l}\text { Ammonium sulfate } \\
\text { fractionation }\end{array}$ & 359 & 514 & $1 \cdot 4$ & $1 \cdot 2$ & $60 \cdot 2$ \\
\hline GPC-75 & 96 & 264 & $2 \cdot 8$ & $2 \cdot 3$ & $31 \cdot 0$ \\
\hline DEAE-Sephadex & 6.6 & 140 & $21 \cdot 2$ & 17.9 & $16 \cdot 3$ \\
\hline QAE-Sephadex & $1 \cdot 4$ & $59 \cdot 6$ & $44 \cdot 1$ & $37 \cdot 2$ & 6.9 \\
\hline \multicolumn{6}{|c|}{ (b) Purification of MTP } \\
\hline Culture broth & 720 & 61490 & 85 & $1 \cdot 0$ & 100 \\
\hline $\begin{array}{l}\text { Ammonium sulfate } \\
\text { fractionation }\end{array}$ & 359 & 36894 & 103 & $1 \cdot 2$ & 60 \\
\hline GPC-75 & 96 & 19062 & 199 & $2 \cdot 3$ & 31 \\
\hline DEAE-Sephadex & $4 \cdot 8$ & 8184 & 1705 & $19 \cdot 9$ & 13 \\
\hline QAE-Sephadex & 1.5 & 5477 & 3651 & $42 \cdot 8$ & 9 \\
\hline
\end{tabular}




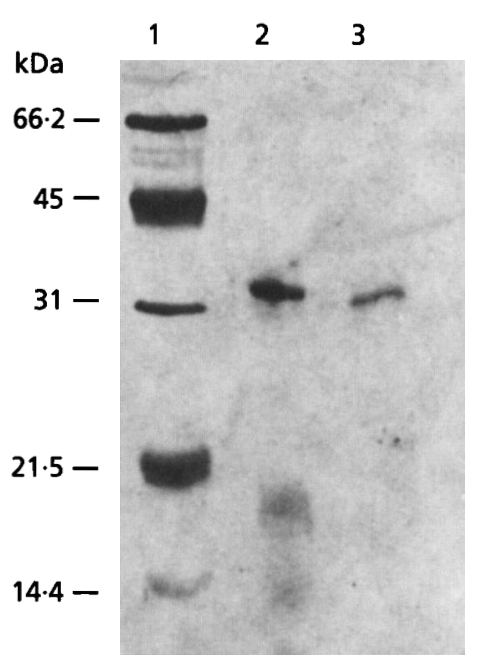

(a)

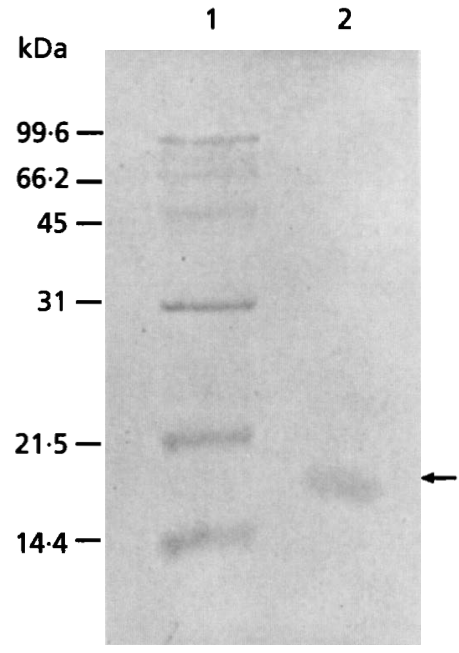

(b)

\begin{abstract}
Fig. 7. SDS-PAGE of purified TLP and MTP. (a) Lanes: 1, standard protein markers; 2, partially purified TLP; 3 , purified TLP. (b) Lanes: 1, standard protein markers; 2 , purified MTP. Standard protein markers are: $99.6 \mathrm{kDa}$, phosphorylase $b$; $66 \mathrm{kDa}, \mathrm{BSA}$; $45 \mathrm{kDa}$, egg albumin; $31.0 \mathrm{kDa}$, carbonic anhydrase; $21.5 \mathrm{kDa}$, soybean trypsin inhibitor; $14.4 \mathrm{kDa}$, hen egg white lysozyme). Arrows point to the purified TLP and MTP.
\end{abstract}

Table 3. Chemical and enzymic properties of purified TLP and MTP

\begin{tabular}{|c|c|c|}
\hline Properties & TLP & MTP \\
\hline Molecular mass & $32 \mathrm{kDa}$ & $18 \mathrm{kDa}$ \\
\hline Optimum pH & 9 & 8 \\
\hline Stable $\mathrm{pH}$ range & $6-9$ & $6-9$ \\
\hline Optimum temperature $\left({ }^{\circ} \mathrm{C}\right)$ & 40 & 55 \\
\hline $\begin{array}{l}\text { Stable temperature range } \\
\left({ }^{\circ} \mathrm{C}\right)\end{array}$ & $4-40$ & $4-55$ \\
\hline$K_{\mathrm{m}}$ & $139 \mu \mathrm{M}$ & $58.9 \mu \mathrm{M}$ \\
\hline$V_{\max }$ & $10 \mathrm{nmol} \mathrm{min}-1$ & $3.47 \mathrm{nmol} \mathrm{min}-1$ \\
\hline$K_{\mathrm{i}}$ of leupeptin & $0.0031 \mu \mathrm{M}$ & \\
\hline
\end{tabular}

Table 4. Effect of metal ions on the activity of TLP and MTP

\begin{tabular}{|c|c|c|}
\hline Metal salts & $\begin{array}{l}\text { Relative activity } \\
\text { (\%) of TLP }\end{array}$ & $\begin{array}{c}\text { Relative activity } \\
(\%) \text { of MTP }\end{array}$ \\
\hline None & 100 & 100 \\
\hline $\mathrm{CaCl}_{2} \cdot 2 \mathrm{H}_{2} \mathrm{O}$ & 110 & 290 \\
\hline $\mathrm{CoCl}_{2} \cdot 6 \mathrm{H}_{2} \mathrm{O}$ & 87 & 450 \\
\hline $\mathrm{CuSO}_{4} \cdot 7 \mathrm{H}_{2} \mathrm{O}$ & 90 & 95 \\
\hline $\mathrm{HgCl}_{2}$ & 15 & 30 \\
\hline $\mathrm{MgSO}_{4} \cdot 7 \mathrm{H}_{2} \mathrm{O}$ & 95 & 92 \\
\hline $\mathrm{MnCl}_{2} \cdot 2 \mathrm{H}_{2} \mathrm{O}$ & 97 & 90 \\
\hline $\mathrm{ZnSO}_{4} \cdot 7 \mathrm{H}_{2} \mathrm{O}$ & 83 & 104 \\
\hline
\end{tabular}

\section{DISCUSSION}

Morphological differentiation in S. albidoflavus SMF301 is accompanied by the sequential production of CTP, TLP and MTP. CTP production appeared to be closely linked to mycelial growth, and a specific inhibitor of CTP inhibited mycelial growth in solid and submerged cultures containing protein as the sole nitrogen source. Since CTP was produced only in cultures containing protein as a sole nitrogen source, and was not detectable in culture broths containing amino acids or inorganic nitrogen sources (data not shown), this enzyme may be essential for hydrolysing proteinaceous nitrogen sources for mycelium growth. A similar role for CTP was demonstrated in $S$. exfoliatus SMF13 (Kim \& Lee, 1995).

Aerial mycelium formation after substrate mycelium growth was inhibited by a TLP inhibitor, and aerial spore formation was inhibited by an MTP inhibitor. Since a bald mutant of $S$. albidoflavus SMF301 was defective in MTP and TLP production (data not shown), it is possible that TLP participates in the formation of aerial mycelium, and MTP participates in the formation of aerial spores. Such a role for TLP might be related to its putative role in utilization of substrate mycelium protein for the growth of aerial mycelium in S. exfoliatus KIS13 (Kim \& Lee, 1995).

Growth and morphological differentiation of $S$. albidoflavus SMF301 in submerged culture depended on the culture conditions. Spores germinated and elongated to form mycelium when nutrients were abundant, but the mycelium differentiated to form spores when some nutrients were limited (Lee \& Rho, 1993; Rho \& Lee, 1994). Submerged spore formation was accompanied by the production of TLP and MTP, and was inhibited by the addition of inhibitors of TLP and MTP. Unusual thickened mycelium resistant to acid and ultrasonication (data not shown) formed when MTP inhibitor was added. This thickening was similar to that occurring in submerged or aerial spores (Lee \& Rho, 1993). The defective production of TLP and MTP in submerged cultures of a bald mutant suggest the possibility that the thickened mycelium is an intermediate between vegetative mycelium and mature spores. TLP might play a role in the formation of thickened mycelium or branching, and MTP might participate in the formation of submerged spores from the thickened mycelium. The temporal relationship between 
(a)

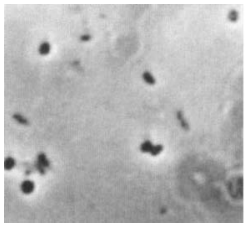

Spore

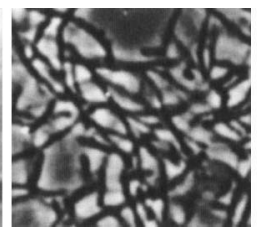

Mycelium

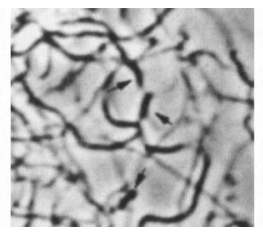

Thickened mycelium

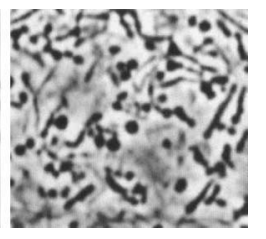

Submerged spore (b)

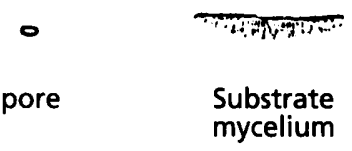

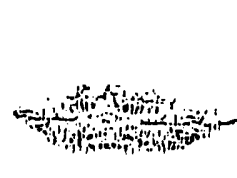

Aerial
mycelium

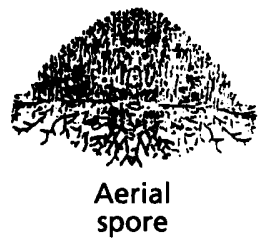

(c)

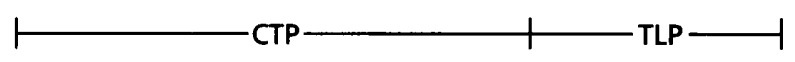

Fig. 8. Morphological differentiation of $S$. albidoflavus SMF13 and production of CTP. TLP and MTP in submerged and solid cultures. (a) Morphological changes in submerged culture (Lee \& Rho, 1993); (b) morphological changes in solid culture (Wildermath, 1970); (c) phases of protease production. the production of CTP, TLP and MTP, and morphological differentiation of S. albidoflavus SMF301 is depicted in Fig. 8. Future work is directed at the genetic analysis of protease production to evaluate its function during differentiation.

\section{ACKNOWLEDGEMENTS}

This work was supported by a research grant from the Research Centre for Molecular Microbiology (RCMM) sponsored by the Korea Science and Engineering Foundation (KOSEF). The authors are very grateful to Professor K. F. Chater for his thoughtful discussion.

\section{REFERENCES}

Aoyagi, T., Miyata, S., Nanbo, M., Kojima, F., Matsuzaki, M., Ishizuka, M., Takeuchi, T. \& Umezawa, H. (1969). Biological activities of leupeptins. $J$ Antibiot 22, 558-568.

Chater, K. F. (1984). Morphological and physiological differentiation in Streptomyces. In Microbial Development, pp. 89-115. Edited by R. Losick \& L. Shapiro. Cold Spring Harbor, NY: Cold Spring Harbor Laboratory.

Chater, K. F. (1989). Multilevel regulation of Streptomyces differentiation. Trends Genet 5, 372-376.

Chater, K. F. (1993). Genetics of differentiation in Streptomyces. Annu Rev Microbiol 47, 685-713.

Daza, A., Martin, J. F., Dominuez, A. \& Gil, J. A. (1989). Sporulation of several species of Streptomyces in submerged culture after nutritional downshift. J Gen Microbiol 135, 2483-2491.

Gibb, G. D. \& Strohl, W. R. (1988). Physiological regulation of protease activity in Streptomyces peucetius. Can $J$ Microbiol 34, 187-190.

Ginther, C. L. (1978). Sporulation and the production of serine protease and cephamycin C by Streptomyces lactamdurans. Antimicrob Agents Chemother 15, 522-526.

Glazebrook, M. A., Doull, J. L., Stuttard, C. \& Vining, L. C. (1990). Sporulation of Streptomyces venezuelae in submerged cultures. $J$ Gen Microbiol 136, 581-588.
Granozzi, C., Billeta, R., Passantino, R., Sollazzo, M. \& Puglia, A. M. (1990). A breakdown in macromolecular synthesis preceding differentiation in Streptomyces coelicolor A3(2). J Gen Microbiol 136, 713-718.

Hara, O. \& Beppu, T. (1982). Mutants blocked in streptomycin production in Streptomyces griseus - the role of A-factor. $J$ Antibiot 35, 349-358.

Hopwood, D. A., Wildermath, H. \& Palmer, H. M. (1970). Mutants of Streptomyces coelicolor defective in sporulation. J Gen Microbiol 61, 397-408.

Hopwood, D. A., Bibb, M. J., Chater, K. F., Kieser, T., Bruton, C. J., Kieser, H. M., Lydiate, D. J., Smith, C. P., Ward, J. M. \& Schrempf, H. (1985). Mutagenesis of Streptomyces spores by ultraviolet light. In Genetic Manipulation of Streptomyces: a Laboratory Manual, pp. 37-38. Norwich: The John Innes Foundation.

Kendrick, K. E. \& Ensign, J. C. (1983). Sporulation of Streptomyces griseus in submerged culture. $J$ Bacteriol 155, 357-366.

Kim, I. S. \& Lee, K. J. (1995). Physiological roles of leupeptin and extracellular proteases in mycelium development of Streptomyces exfoliatus SMF13. Microbiology 141, 1017-1025.

Koepsel, R. \& Ensign, J. C. (1984). Microcycle sporulation of Streptomyces viridochromogenes. Arch Microbiol 140, 9-14.

Lee, K. J. \& Rho, Y. T. (1993). Characteristics of spores formed by solid and submerged cultures of Streptomyces albidoflavus SMF301. $J$ Gen Microbiol 139, 3131-3137.

Mendez, C., Brana, A. F., Manzanal, M. B. \& Hardisson, C. (1985). Role of substrate mycelium in colony development in Streptomyces. Can J Microbiol 31, 446-450.

Narahashi, Y. (1970). Pronase. Methods Enzymol 19, 651-664.

Rho, Y. T. \& Lee, K. J. (1994). Kinetic characterization of sporulation in Streptomyces albidoflavus SMF301 during submerged culture. Microbiology 140, 2061-2065.

Rho, Y. T., Kim, H. T., Oh, K. H., Kang, H. I., Ward, A. C., Goodfellow, M., Hah, Y. C. \& Lee, K. J. (1992). Numerical identification of a Streptomyces strain producing spores in submerged culture. Korean J Microbiol 30, 278-285.

Sarath, G., De La Motte, R. S. \& Wagner, F. W. (1989). Protease assay methods. In Proteolytic Enzymes: a Practical Approach, pp. 
25-55. Edited by R. J. Beynone \& J. S. Bond. Oxford, New York \& Tokyo: IRL Press.

Shaprio, S. (1989). Nitrogen assimilation in actinomycetes and the influence of nitrogen nutrition on actinomycete secondary metabolism. In Regulation of Secondary Metabolism in Actinomycetes, pp. 149-153. Edited by S. Shapiro. Boca Raton, FL: CRC press.
Wildermath, H. (1970). Development and organization of the aerial mycelium in Streptomyces coelicolor. J Gen Microbiol 60, 43-50.

Received 17 February 1995; revised 21 August 1995; accepted 25 August 1995. 